\title{
O contraste acentual nos verbos no português brasileiro: análise pela Fonologia Métrica e pela Teoria da Otimidade
}

DOI: http://dx.doi.org/10.21165/el.v49i3.2720

\section{Fernanda Alvarenga Rezende'}

\section{Resumo}

Este estudo teve como principal objetivo tratar do acento verbal no português brasileiro (PB), com destaque ao contraste acentual presente nesta classe de palavras. Para a análise, nos baseamos no modelo de restrições da Teoria da Otimidade (TO), na Fonologia Métrica (HAYES, 1995) e nas análises de Magalhães $(2004,2010)$ para os não-verbos. O resultado da análise mostrou que o contraste acentual dos verbos é bem representado pelas restrições morfológicas, por demonstrarem a interface morfologia-fonologia e garantirem que o acento recaia na posição correta, de acordo com cada tempo verbal.

Palavras-chave: contraste acentual; verbos; português brasileiro.

1 Universidade Federal de Uberlândia (UFU), Uberlândia, Minas Gerais, Brasil; fernandaalvarenga87@gmail.com; https://orcid.org/0000-0001-8272-5811 


\title{
The stress contrast in Brazilian Portuguese verbs: analysis by Metrical Phonology and Optimality Theory
}

\begin{abstract}
In this study, we deal with the verb stress in Brazilian Portuguese (BP), highlighting the stress contrast present in this class of words. For the analysis, we based on the Optimality Theory (OT) constraints model, on the Metrical Phonology (HAYES, 1995) and Magalhães $(2004,2010)$ non-verbs analysis. The result of the analysis showed that the stress contrast of the verbs is well represented by the morphological constraints, as they demonstrate the morphology-phonology interface and ensure that the stress falls in the correct position, according to each verb tense.
\end{abstract}

Keywords: stress contrast; verbs; Brazilian Portuguese.

\section{Introdução}

O acento em português é um sistema que apresenta muita irregularidade e, por isso, foi e ainda é muito estudado. Trabalhos como o de Mateus (1983), Bisol (1992, 1994), Lee (1994, 2007) e Massini-Cagliari (1995, 1999, 2005), bastante conhecidos na literatura, lidam tanto com o acento não-verbal quanto com o acento verbal. Neste estudo, o objeto de análise é o acento dos verbos, mais especificamente, o contraste acentual nos verbos do português brasileiro (PB), que é resultado da interação entre a morfologia e a fonologia.

Esse contraste aparece em verbos como "batera" (da primeira e da terceira pessoas do singular do pretérito mais-que-perfeito do indicativo) com acento paroxítono e "baterá" (da terceira pessoa do singular do futuro do presente do indicativo) com acento oxítono e em "dorme" (da terceira pessoa do singular do presente do indicativo) com acento paroxítono e "dormi" (da primeira pessoa do singular do pretérito perfeito do indicativo) com acento oxítono.

Deslocamentos de acento como esses representam exemplos de contrastes acentuais que apresentamos em tableaux, na análise que desenvolvemos baseada na Teoria da Otimidade (TO), de McCarthy e Prince (1993a, 1993b), Prince e Smolensky (1993) e Kager (1999), assim como nas propostas de Hyde (2001) acerca das restrições de alinhamento e de Magalhães $(2004,2010)$ sobre os não-verbos do português. Além da TO, para a análise do acento primário dos verbos no português brasileiro, que é o principal objetivo

2 Trabalho advindo da tese intitulada Caracterização métrica e gramática de restrições do acento verbal no português brasileiro, defendida em 02 de março de 2018, no Programa de Pós-graduação em Estudos Linguísticos da Universidade Federal de Uberlândia. 
desta pesquisa, também nos pautamos na Fonologia Métrica, de Hayes (1995). Tanto a TO quanto a Fonologia Métrica são importantes para a análise, uma vez que, neste trabalho, utilizamos os parâmetros desta teoria de acento para selecionar ou criar, em alguns casos, as restrições da TO que aparecem nos tableaux.

Os objetivos específicos que nortearam este estudo foram três, quais sejam: estabelecer uma interação entre a fonologia e a morfologia, por meio da atuação de restrições morfológicas e fonológicas; analisar os contrastes de acento nos verbos (ex.: entre "bati" e "bate" e entre "parti" e "parte"), por mostrarem a relevância da informação morfológica para distinguir tempos verbais; e propor uma hierarquia de restrições para o sistema verbal do PB no que se refere ao acento.

Em relação às hipóteses, formulamos três que buscamos confirmar ou refutar no decorrer deste estudo, quais sejam: 1) as informações morfológicas são fundamentais para o acento dos verbos; 2) as restrições de alinhamento são a base da hierarquia de restrições para captar o acento verbal; 3) o acento é previsível de acordo com o tempo verbal analisado. Além das hipóteses, pretendíamos responder a seguinte questão: na análise do acento verbal, sobretudo, em relação ao contraste acentual, qual é o papel das restrições morfológicas?

Este artigo foi organizado em quatro seções. Na primeira, tratamos da fundamentação teórica, com uma breve apresentação da Fonologia Métrica, especificamente o modelo de Hayes (1995), e da Teoria da Otimidade (McCARTHY; PRINCE, 1993a, 1993b; PRINCE; SMOLENSKY, 1993; KAGER, 1999; HYDE, 2001). Na segunda seção, discorremos sobre o acento verbal no PB com base nas duas teorias citadas. Ademais, apresentamos a caracterização métrica do acento dos verbos no português brasileiro e, em seguida, listamos as restrições envolvidas na análise. O assunto da terceira seção são a análise e a hierarquia de restrições do acento verbal no PB. Por fim, estão as considerações finais e as referências que foram fundamentais para a construção deste trabalho.

\section{Fundamentação teórica}

\section{A Fonologia Métrica: o modelo de Hayes (1995)}

Para Hayes (1995), o pé é o menor constituinte na estrutura métrica. Por isso, a proposta do autor contém três tipos de pés: o troqueu silábico, o iambo e o troqueu mórico. Esses pés são parametricamente sistematizados e seriam suficientes para captar a estrutura rítmica das línguas. A seguir, caracterizamos cada um dos tipos de pé propostos por Hayes (1995, p. 63): 
* Troqueu silábico: é um "pé dissilábico com proeminência inicial".

\author{
$(x$.) \\ Troqueu silábico: $\sigma \quad \sigma$
}

* lambo: pode conter duas sílabas no máximo, de modo que a mais forte está à direita. Em um pé dissilábico, o membro esquerdo deve ser uma sílaba leve.
(. $\mathrm{x})$
$(x)$
lambo: Forme
$\sigma$ se possível; se não, forme

* Troqueu mórico: duas sílabas leves equivalem a uma sílaba pesada. Este troqueu leva em conta o peso silábico e é constituído por um pé com duas moras.

$$
\text { Troqueu mórico: } \stackrel{(x)}{ } \quad \text { ou } \stackrel{(x)}{-}
$$

A existência desses três tipos de pé não impede que algumas línguas proíbam pés "degenerados", que são definidos por Hayes (1995, p. 86) como os menores pés logicamente possíveis. Em (1), apresentamos a formulação preliminar de pé degenerado feita pelo autor:

\section{(1) a. Troqueu silábico}

$(\mathrm{x})$ b. Troqueu mórico

$(x)$

\section{C. lambo}

$(\mathrm{x})$

A consequência de não se permitir os pés degenerados é que muitas palavras terão sílabas deixadas fora do pé. Por isso, Hayes (1995, p. 87) propõe que as línguas proíbam os pés degenerados em níveis diferentes, uma vez que há línguas cuja proibição é forte, por não admitirem esse tipo de pé, e outras em que a proibição é fraca, porque a permissão ocorre quando esses pés são dominados por outra marca de grade. A configuração de pé degenerado adotada por Hayes (1995, p. 102) aparece em (2) e mostra um pé formado por uma sílaba leve:

\title{
(2) Pé degenerado ( $x$ )
}

Em sua Teoria Métrica Paramétrica, Hayes (1995, p. 54-55) propõe que unidades menores que a sílaba não podem portar acento, de modo que "[...] um sistema de regra é considerado 
como uma escolha particular de uma lista limitada de opções ou parâmetros", tais como: "a direção da escansão", que pode ser da esquerda para a direita ou da direita para a esquerda, e "a iteratividade", cuja construção do pé pode ser iterativa (interpreta-se essa construção até onde der) ou não-iterativa (um único pé é construído e para-se nele).

A seguir, tratamos da Teoria da Otimidade, mais conhecida como TO. Além desta teoria, também apresentamos as principais contribuições dos trabalhos de Magalhães (2004, 2010), que tiveram a TO e a Fonologia Métrica como base teórica.

\section{A Teoria da Otimidade}

Foi na Fonologia que a Teoria da Otimidade (TO) mais se desenvolveu, embora não seja uma teoria exclusiva dessa área. Segundo Kager (1999, p. XI), a ideia central da TO é "[...] que as formas de superfície da língua refletem as resoluções de conflitos entre a competição de exigências ou restrições". Os dois principais tipos de restrições com os quais a TO lida são as restrições de fidelidade e as restrições de marcação. As primeiras "[...] requerem que os outputs preservem as propriedades de suas formas (lexicais) básicas, exigindo algum tipo de similaridade entre o output e seu input" - como MAX (não apague); DEP (não insira) e IDENT(F)³ (os traços dos segmentos não devem ser mudados). Já as restrições de marcação exigem "[...] que as formas de output encontrem algum critério de boa formação estrutural" (KAGER, 1999, p. 9-10) - como PEAK (as sílabas devem conter uma vogal no núcleo) e ONSET (as sílabas devem conter ataque). Portanto, a gramática da TO pode ser definida como "[...] um mecanismo de input-output que une uma forma de output a uma forma de input (de modo que cada input tenha precisamente um output)" (KAGER, 1999, p. 18).

A TO também conta com um conjunto de restrições que fazem parte de uma subteoria conhecida como Alinhamento Generalizado ${ }^{4}(\mathrm{AG})$, que éa que nos interessa especialmente neste estudo. Segundo Russell (1997, p. 119), "ALINHE não é uma restrição, é um esquema para criar restrições". Esse esquema contém duas categorias e duas bordas com as quais elas devem ser alinhadas:

(3) Esquema do Alinhamento Generalizado (RUSSELL, 1997, p. 119)

ALINHE (Categoria ${ }_{1}$, Borda $_{1}$, Categoria ${ }_{2}$, Borda $_{2}$ )

Onde Categoria ${ }_{1}$ e Categoria ${ }_{2}$ são categorias prosódicas ou gramaticais e Borda e Borda $_{2}$ podem ser esquerda ou direita.

Interpretação: para todos os casos da Categoria ${ }_{1}$, há algum caso da Categoria ${ }_{2}$ e a Borda da Categoria ${ }_{1}$ se alinha com a Borda ${ }_{2}$ da Categoria $_{2}$.

3 A letra "F" corresponde ao substantivo inglês feature, que, nesse contexto, significa traço.

4 Do inglês Generalized Alignment (McCARTHY; PRINCE, 1993b). 
A partir das premissas básicas da Fonologia Métrica e da Teoria da Otimidade, Magalhães $(2004,2010)$ analisa os não-verbos no português brasileiro. Na análise proposta pelo autor, as restrições envolvidas para captar os fatos do padrão regular de acento dos nomes no português brasileiro (ex.: "calor", "casaco") são: PrWd-RIGHT (a borda direita de cada palavra prosódica é alinhada com a borda direita do cabeça de algum pé); GRID$\mu \mathrm{HEAD}$ (uma marca de grade (x) deve ocupar a mora cabeça de algum pé); PROJECTSONORANT (toda soante pertencente a algum pé deve projetar uma posição na grade (por extensão, uma mora)); PARSE- $\sigma$ (toda sílaba deve ser escandida em algum pé) e *SHARED- $\mu$ (cada segmento na rima deve projetar sua própria mora (proibido mora compartilhada em qualquer sílaba)) (MAGALHÃES, 2010, p. 122).

As palavras paroxítonas terminadas em consoante obstruinte (ex.: "pires"); as paroxítonas terminadas em consoante soante (ex:: "líder") e as proparoxítonas (ex.: "fôlego") representam o padrão irregular dos nomes. Segundo Magalhães (2010, p. 126-127), as restrições STRESSFAITHFULNESS (o acento do input mantém-se na mesma posição no

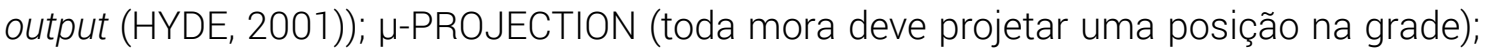
PROJECT-OBSTRUENT (toda obstruinte pertencente a algum pé deve projetar uma marca de grade); *SHAREDH-WEAK (cada segmento na rima deve projetar sua própria mora em sílaba não acentuada (proibido mora compartilhada em sílaba não acentuada)); PROJECT-SONORANT (toda soante pertencente a algum pé deve projetar uma posição na grade (por extensão, uma mora)); RIGHTMOST (alinhe a borda direita da palavra prosódica com a borda direita do pé cabeça (o pé mais proeminente da palavra está na borda direita)) e DEP- $\mu$ (proibido inserir mora) atuam na gramática em favor do padrão irregular de acento dos nomes no PB.

Diferentemente de outros estudos, como os de Bisol (1992, 1994), nos trabalhos de Magalhães $(2004,2010)$ não há referência à extrametricidade. O acento de palavras como "fôlego" é captado por uma restrição altamente ranqueada chamada STRESSFAITHFULNESS, que exige fidelidade do acento do input no output. Assim, a hierarquia de restrições que Magalhães (2010, p. 133) propõe para o acento dos nomes no PB é a seguinte: DEP >> STRESSFAITH, RIGHTMOST, *SHARED $\mu-W E A K ~>>$ PrWdRIGHT, GRID- $\mu$ HEAD > > PARSE- $\sigma$, PROJOBST, $\mu$-PROJ > > *SHARED- $\mu$.

Na seção seguinte, apresentamos a caracterização métrica e as restrições importantes para a análise do acento verbal no PB.

\section{A caracterização métrica e as restrições que compõem a análise do acento dos verbos no PB}

A acentuação dos verbos em português não pode ser generalizada por meio de uma única regra. Wetzels (2007) explica que, nos tempos do passado, o acento recai na vogal imediatamente seguinte à raiz (a vogal tônica está em itálico): "falávamos". Nos 
tempos do futuro, a primeira sílaba do sufixo futuro é acentuada: "partirá". Nos tempos do presente, há duas regras: a vogal temática recebe acento na primeira e na segunda pessoa do plural (ex.: "batemos"; "bateis") e, nos demais contextos, acentua-se a última vogal da raiz (ex.: "parte").

Para Bisol (1994), as sílabas em português são estruturadas em pés métricos binários de cabeça à esquerda, representados como (* .), em que o asterisco indica a sílaba dominante e o ponto a sílaba dominada. No modelo métrico de Hayes (1995), a proposta da autora é representada por um troqueu. Os pés são construídos da direita para a esquerda, não-iterativamente e a extrametricidade pode atingir segmentos ou sílabas por meio de uma regra específica. Os parâmetros em (4), a seguir, foram baseados na perspectiva da Teoria Métrica Paramétrica (HAYES, 1995) e na proposta deste estudo, e seriam suficientes para captar os fatos referentes ao acento primário dos verbos no PB:

(4) a. Construção do pé: Forme um troqueu silábico não-iterativo da direita para a esquerda.

Pés degenerados são permitidos apenas na posição forte, quando o pé canônico não puder ser formado (proibição fraca).

b. Extrametricidade: a desinência de plural na $1^{\mathrm{a}}$ e $2^{\mathrm{a}}$ pessoas do plural dos verbos dos tempos do imperfeito, do mais-que-perfeito e do futuro do pretérito do indicativo. Nos casos restantes, a consoante final com status de desinência, ou seja, N ou $S$.

c. Regra Final: à direita.

A configuração em (5), a seguir, foi baseada na proposta de Bisol $(1992,1994)$ e nos parâmetros em (4):

(5) Representação métrica do acento primário dos verbos que apresentam contraste acentual no PB
a) Presente do indicativo: $(x) \quad(x)$
ba.te par.te
b) Pretérito perfeito do indicativo:
$(\mathrm{x})$
$(\mathrm{x})$
ba.ti par.ti
c) Pretérito mais-que-perfeito do indicativo: $\quad(x \quad$.)
fa.la.ra
d) Futuro do presente do indicativo:
$(x)$

fa.la.rá

A representação métrica em (5), interpretada pelo modelo de Hayes (1995), permitiu-nos tecer as generalizações em (6): 
(6)

* o pé básico é o troqueu silábico;

* os pés são maximamente dissilábicos, ou seja, podem ter uma ou duas sílabas;

* pés degenerados são permitidos;

* cada tempo verbal tem a sua acentuação própria;

* o fato de uma sílaba ser de rima ramificada não implica que ela receberá acento;

* o acento recai na vogal da raiz, na vogal temática (que, neste trabalho, denomina também a primeira vogal imediatamente seguinte à vogal da raiz) ou na vogal do sufixo flexional, conforme o tempo verbal e, em alguns casos, a pessoa do verbo;

* o acento faz referência explícita ao contexto morfológico.

Ao contrário da Fonologia Métrica, que é um modelo que opera com regras, a Teoria da Otimidade é baseada em restrições universais que definem a gramática particular de uma língua, por meio de ranqueamento. Desse modo, em uma análise amparada teoricamente pela TO, as restrições envolvidas são sugeridas através de generalizações descritivas, como as que apresentamos em (6). Isso acontece porque são os fatos da língua que sugerem quais restrições farão parte da análise. Para selecionar ou, em alguns casos, criar as restrições da análise feita a partir da TO, neste trabalho, também utilizamos os parâmetros da Fonologia Métrica, apresentados em (4).

Assim, em (7), apresentamos as nove restrições consideradas relevantes para a análise do acento verbal no PB:

(7) TROQUEU: os pés têm proeminência inicial.

FOOTBINARITY (FTBIN): os pés são binários no nível da sílaba.

PARSE-б: todas as sílabas devem ser escandidas em pés.

RIGHTMOST: Alinhe (PrWd, R, Hd(PrWd), R): alinhe a borda direita da palavra prosódica com a borda direita do pé cabeça (o pé mais proeminente da palavra está na borda direita).

ALINHE-SUFIXO (Futuro): Alinhe (Afixo, Borda Esquerda, Palavra Prosódica, Borda Direita): alinhe a borda esquerda de cada sufixo com a borda direita de uma palavra prosódica.

SNONFINALITY ou NONFIN (Pé-GM, Sílaba, PrWd): Cada marca de grade no nível do pé tem uma categoria descendente silábica no domínio da palavra prosódica.

PrWd-RIGHT ou Alinhe (PrWd, R, Ft-Hd, R): a borda direita de cada palavra prosódica é alinhada com a borda direita do cabeça de algum pé.

ALINHE-TEMA: ALINHE (PrWd, D, Tema (PrWd), D): Alinhe a borda direita da palavra prosódica com a borda direita do tema verbal.

*FINALIDADE(Presente): Proibido acento final nos verbos do presente (indicativo e subjuntivo). 
A análise baseada no modelo de restrições da TO e nos parâmetros da Fonologia Métrica e a hierarquia de restrições que propomos para o acento verbal no PB são o assunto da seção seguinte.

\section{Análise do acento verbal no PB e a proposta de uma hierarquia de restrições}

A partir das restrições apresentadas em (7), nesta seção, fazemos a análise e, em seguida, propomos uma hierarquia de restrições para o acento verbal no PB, com destaque aos verbos que têm contrastes acentuais. A base para cumprirmos esse objetivo são os parâmetros apresentados em (4), referentes à construção do pé, à extrametricidade, que atinge tempos verbais específicos, e à Regra Final. Nos tableaux, a seguir, os exemplos são de Wetzels (2007).

Iniciamos a análise com o contraste acentual entre os verbos "bati" e "bate", que representam os verbos da segunda conjugação. Vejamos, no tableau (8), a análise do verbo "bati", que pertence à primeira pessoa do singular do pretérito perfeito do indicativo.

Tableau (8): Verbo "bati" (/bat] $\left.]_{\text {raiz }}\right]_{\text {tema }} /$ )

\begin{tabular}{|c|c|c|c|c|c|c|c|}
\hline /bat+i/ & $\begin{array}{l}\text { ALINHE- } \\
\text { TEMA }\end{array}$ & $\begin{array}{l}\text { RIGHT } \\
\text { MOST }\end{array}$ & TROQUEU & $\begin{array}{c}\text { SNON } \\
\text { FINALITY }\end{array}$ & $\begin{array}{l}\text { PrWd- } \\
\text { RIGHT }\end{array}$ & FTBIN & PARSE- $\sigma$ \\
\hline $\begin{array}{r}(x) \\
\text { a. ba.ti }\end{array}$ & & & & * & & * & * \\
\hline $\begin{array}{r}(. x) \\
\text { b. ba.ti }\end{array}$ & & & *! & * & & & \\
\hline $\begin{array}{r}(x .) \\
\text { c. ba.ti } \\
V\end{array}$ & *! & & & * & * & & \\
\hline
\end{tabular}

A restrição RIGHTMOST é satisfeita por todos os candidatos do tableau (8), que, por sua vez, violam SNONFINALITY. O candidato (8c) é eliminado por não acentuar a vogal temática, o que é exigido pela restrição mais alta. Embora satisfaça a exigência desta restrição, o candidato (8b) constrói um pé iâmbico na borda direita, o que viola TROQUEU e elimina esse candidato. 0 candidato (8a) satisfaz as três restrições mais altas e viola apenas as mais baixas, sendo, portanto, o vencedor da competição. 
Em (9), apresentamos a análise para o verbo "bate", da terceira pessoa do singular do presente do indicativo, cujo contraste foi apresentado em (8), com "bati".

Tableau (9): Verbo "bate" (/bat $]_{\text {raiz }}$ e/)

\begin{tabular}{|c|c|c|c|c|c|c|c|}
\hline /bat+e/ & ${ }^{\star} \mathrm{FIN}(\mathrm{Pr})$ & $\begin{array}{l}\text { RIGHT } \\
\text { MOST }\end{array}$ & TROQUEU & $\begin{array}{c}\text { SNON } \\
\text { FINALITY }\end{array}$ & $\begin{array}{l}\text { PrWd- } \\
\text { RIGHT }\end{array}$ & FTBIN & PARSE- $\sigma$ \\
\hline $\begin{array}{c}(x \quad .) \\
\text { a. ba.te }\end{array}$ & & & & * & * & & \\
\hline 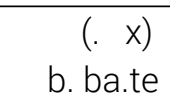 & *! & & * & * & & & \\
\hline $\begin{array}{r}(x) \\
\text { c. ba.te }\end{array}$ & *! & & & * & & * & * \\
\hline
\end{tabular}

Os três candidatos do tableau (9) escandem a sílaba final e, por isso, violam SNONFINALITY. A restrição *FIN(Pr), ranqueada mais alto e que garante a atonicidade da sílaba final nos verbos dos tempos do presente, só é satisfeita pelo candidato (9a). Esse candidato comete apenas duas violações e, por satisfazer as três restrições mais altas, é o vencedor. Os candidatos (9b) e (9c) são eliminados, por violarem a restrição mais alta. O candidato (9c) também viola FTBIN e PARSE- $\sigma$, porque, como o pé construído é um monossílabo, uma sílaba não é escandida. O candidato (9b) constrói um iambo e viola TROQUEU.

Em (10), o verbo "parti" representa as formas verbais da primeira pessoa do singular do pretérito perfeito do indicativo da terceira conjugação.

Tableau (10): Verbo "parti" (part] $\left.]_{\text {raiz }}\right]_{\text {tema }}$ )

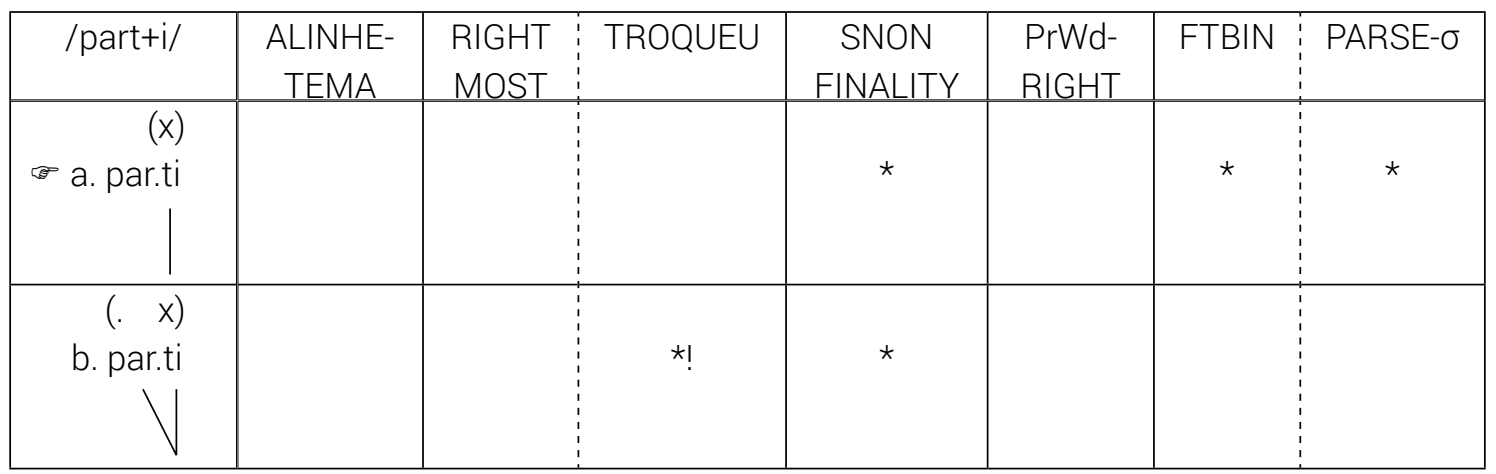




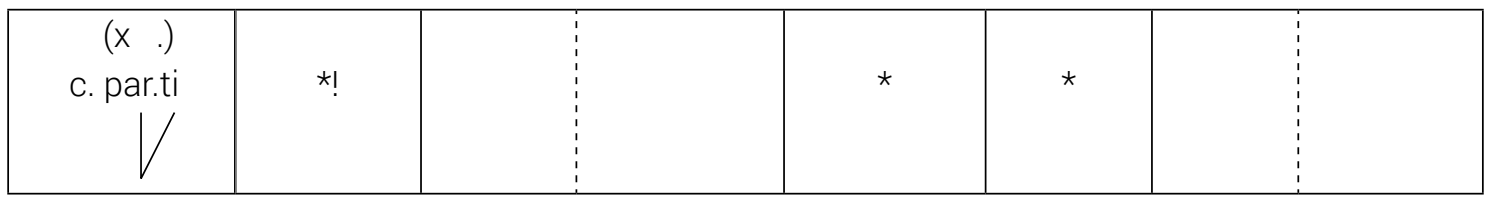

No tableau (10), todos os candidatos constroem o pé na borda direita e escandem a sílaba final, portanto, respectivamente, satisfazem RIGHTMOST e violam SNONFINALITY. O candidato (10c) constrói um pé troqueu canônico, mas não acentua a vogal temática, o que resulta na violação de ALINHE-TEMA e, consequentemente, na eliminação desse candidato. O candidato (10b) satisfaz duas das restrições mais altas, mas, ao construir um iambo, comete uma violação fatal para TROQUEU e também deixa a competição. O candidato (10a) constrói um pé troqueu na borda direita e acentua a vogal temática, satisfazendo, portanto, as três restrições mais altas e sendo eleito o vencedor da competição.

Em verbos como "parti" e "perdi", nos quais a vogal acentuada é a vogal temática, Massini-Cagliari (2005) e Lee (2007) propuseram as restrições ALINHE (Tema, D, PrWd, D) e PU (Uniformidade Paradigmática, em português), respectivamente, para captar esta acentuação e que são altamente ranqueadas nesses dois trabalhos. No entanto, para Lee (1994), os verbos oxítonos terminados em vogal são considerados casos marcados para o acento verbal.

O verbo "parti", no tableau (10), contrasta com outro verbo dos tempos do presente. Em (11), apresentamos a análise do verbo "parte", da primeira pessoa do singular do presente do indicativo e que é acentuado na vogal do radical, assim como o verbo "bate", em (9).

Tableau (11): Verbo "parte" (/part] $]_{\text {raiz }}$ e/)

\begin{tabular}{|c|c|c|c|c|c|c|c|}
\hline /part+e/ & ${ }^{\star} \mathrm{FIN}(\mathrm{Pr})$ & $\begin{array}{l}\text { RIGHT } \\
\text { MOST }\end{array}$ & TROQUEU & $\begin{array}{c}\text { SNON } \\
\text { FINALITY }\end{array}$ & $\begin{array}{l}\text { PrWd- } \\
\text { RIGHT }\end{array}$ & FTBIN & PARSE- 0 \\
\hline 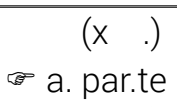 & & & & * & * & & \\
\hline $\begin{array}{l}(. \quad x) \\
\text { b. par.te }\end{array}$ & $\star !$ & & * & $\star$ & & & \\
\hline $\begin{array}{c}(\mathrm{x}) \\
\text { c. par.te }\end{array}$ & & *! & & & * & * & * \\
\hline
\end{tabular}


No tableau (11), o candidato (11b) é eliminado por violar a restrição *FIN(Pr), já que acentua a sílaba final. Esse candidato também viola TROQUEU, por construir um iambo, e SNONFINALITY, por escandir a última sílaba. Os candidatos (11a) e (11c) satisfazem a restrição *FIN(Pr), mas o candidato (11c) constrói um pé degenerado a uma sílaba de distância da borda direita. Assim, a restrição RIGHTMOST é violada e o candidato é eliminado. Como constrói um pé troqueu canônico na borda direita e acentua a vogal do radical, o que satisfaz as três restrições mais altas, o candidato (11a) vence a competição.

Por fim, apresentamos o contraste acentual entre "partirá", da terceira pessoa do singular do futuro do presente do indicativo, e "partira", da primeira e da terceira pessoas do singular do pretérito mais-que-perfeito do indicativo. Contrastes como esse e os demais já apresentados neste trabalho (entre "bati" e "bate" e entre "parti" e "parte") são, segundo Mateus e d'Andrade (2000), argumentos que indicam que o português não é uma língua sensível ao peso silábico, mas também ressaltam a relevância da informação morfológica para distinguir tempos verbais.

O tableau (12) contém a análise do verbo "partirá", da terceira conjugação.

Tableau (12): Verbo partirá (part] raiz $_{\text {iz }}$ tema $^{\text {ra) }}$

\begin{tabular}{|c|c|c|c|c|c|c|c|}
\hline /part+i+ra/ & $\begin{array}{l}\text { ALINHE- } \\
\text { SUF(F) }\end{array}$ & $\begin{array}{l}\text { RIGHT } \\
\text { MOST }\end{array}$ & TROQUEU & $\begin{array}{c}\text { SNON } \\
\text { FINALITY }\end{array}$ & $\begin{array}{l}\text { PrWd- } \\
\text { RIGHT }\end{array}$ & FTBIN & PARSE- $\sigma$ \\
\hline $\begin{array}{r}(\mathrm{x}) \\
\sigma \text { a. par.ti.ra }\end{array}$ & & & & * & & * & $\star \star$ \\
\hline $\begin{array}{r}(x .) \\
\text { b. par.ti.ra }\end{array}$ & $\star !$ & & & * & * & & * \\
\hline $\begin{array}{r}\left(\begin{array}{l}\text { x }\end{array}\right) \\
\text { c. par.ti.ra }\end{array}$ & & & $\star !$ & * & & & * \\
\hline $\begin{array}{c}(x \quad .) \\
\text { d. par.ti.ra } \\
V\end{array}$ & $\star !$ & * & & & $\star \star$ & & * \\
\hline
\end{tabular}

Por ser um verbo dos tempos do futuro, "partirá" deve ser acentuado na vogal inicial da desinência de futuro. Como não atendem essa exigência, os candidatos (12b) e (12d) são eliminados. Esses dois candidatos também violam PrWd-RIGHT e PARSE- $\sigma$, que, neste 
tableau, não é satisfeita por nenhum dos candidatos. Além dessas violações, o candidato (12d) não constrói um pé na borda direita e viola RIGHTMOST. O candidato (12c) satisfaz duas das três restrições mais altas, mas constrói um iambo na borda direita e é eliminado por TROQUEU. O candidato (12a) é o vencedor, porque constrói um pé degenerado na borda direita e acentua a primeira vogal do sufixo flexional.

Em (13), o verbo "partira" exemplifica as formas verbais do pretérito mais-que-perfeito do indicativo, da primeira e da terceira pessoas do singular. Apesar de tanto "partirá" quanto "partira" pertencerem à terceira conjugação, os contrastes acentuais também ocorrem com verbos da primeira (ex.: "falará" e "falara") e da segunda conjugação (ex.: "baterá" e "batera").

Tableau (13): Verbo partira (part] $]_{\text {raiz }}$ i $]_{\text {tema }}$ ra)

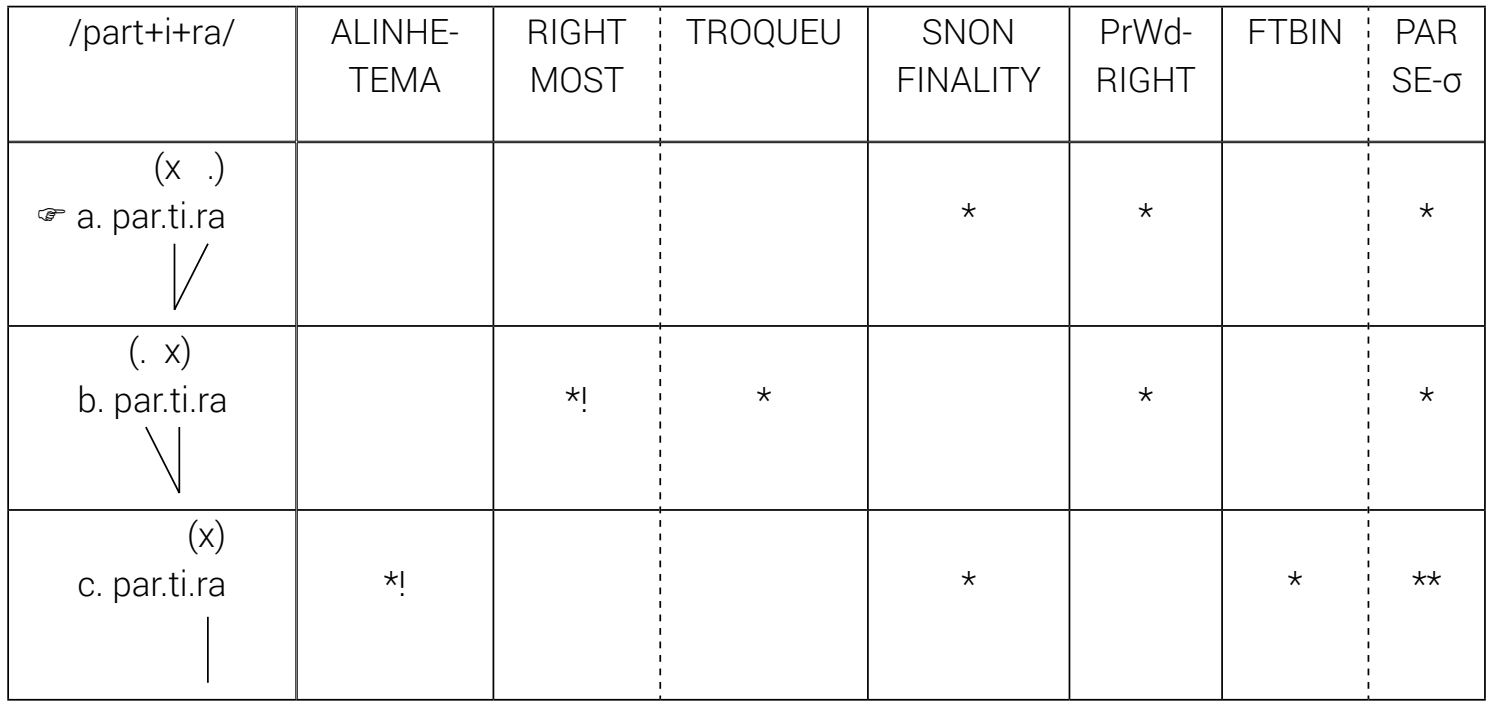

Em (13), todos os candidatos violam a restrição PARSE- $\sigma$. O candidato (13b) satisfaz a restrição ALINHE-TEMA, a mais alta, já que acentua a vogal temática, entretanto, constrói um iambo a uma sílaba de distância da borda direita e é eliminado por violar RIGHTMOST e TROQUEU. A restrição RIGHTMOST é satisfeita pelos candidatos (13a) e (13c), mas, ao construir um pé degenerado e não acentuar a vogal temática, (13c) viola ALINHETEMA e deixa a competição. O candidato (13a) viola SNONFINALITY e PrWd-RIGHT, mas vence a disputa, porque o pé troqueu canônico construído na borda direita contém a vogal temática acentuada.

Para cumprir um dos objetivos deste estudo, a análise que desenvolvemos nos permitiu gerar, em (14), a hierarquia de restrições do acento dos verbos no português brasileiro, com destaque aos verbos que apresentam contraste acentual. 
(14) Hierarquia de restrições proposta para o acento verbal no PB

ALINHE-SUF(F), ALINHE-TEMA, *FIN(Pr) >> RIGHTMOST, TROQUEU >> SNONFINALITY > PrWd-RIGHT > FTBIN, PARSE- $\sigma$.

A seguir, apresentamos as considerações finais.

\section{Considerações finais}

Todas as hipóteses formuladas no início deste trabalho foram confirmadas pelos resultados que obtivemos. Isso porque o acento verbal é previsível e faz referência explícita ao contexto morfológico, já que depende das características acentuais dos morfemas flexionais para que sua posição seja determinada. Assim, as restrições morfológicas de alinhamento ranqueadas no topo da hierarquia reforçam a importância do condicionamento morfológico para atribuir o acento aos verbos e, assim, garantir que o paradigma de cada tempo verbal seja respeitado. Neste trabalho, essas restrições são: ALINHE-SUFIXO (Futuro), ALINHE-TEMA e *FINALIDADE (Presente).

Embora a maioria dos verbos seja paroxítona, há casos em que o acento precisa se deslocar para evitar que duas formas verbais de tempos diferentes tenham a mesma pronúncia, como em "partira" (da primeira e da terceira pessoas do singular do pretérito mais-que-perfeito do indicativo) com acento paroxítono e "partirá" (da terceira pessoa do singular do futuro do presente do indicativo) com acento oxítono. Esse tipo de deslocamento representa um dos exemplos de contrastes acentuais que apresentamos nos tableaux e parece ser a melhor opção para o acento, visto que não há muitos casos de verbos acentuados na antepenúltima sílaba.

Ademais, os contrastes mostram a interação entre a morfologia e a fonologia, que é representada pela presença das restrições de alinhamento na hierarquia. Autores como Bisol $(1992,1994)$ e Lee $(1994,2007)$ não consideraram esses contrastes acentuais em seus trabalhos, talvez porque tinham como objetivo descrever o padrão de acento dos verbos e dos não-verbos de um modo geral e, no caso de Bisol $(1992,1994)$, sem contar com a TO.

Na hierarquia que propusemos em (14), as restrições RIGHTMOST e TROQUEU são altamente ranqueadas e atuam juntas para que um pé trocaico seja construído na borda direita da palavra, que é o padrão da maioria dos verbos. Em conflito com estas duas restrições está SNONFINALITY, cuja exigência é de que a sílaba final não seja escandida. Logo em seguida, está PrWd-RIGHT, que requer que o cabeça do pé esteja na borda direita da palavra prosódica. As restrições mais baixas, e não menos importantes, são FTBIN e PARSE- $\sigma$, pois nem sempre o melhor candidato constrói um pé binário e a escansão das sílabas é não-iterativa, ou seja, um único pé é construído e para-se nele. 
Portanto, em resposta à pergunta norteadora deste estudo, podemos afirmar que o contraste acentual dos verbos é bem representado pelas restrições morfológicas, por demonstrarem a interface morfologia-fonologia e garantirem que o acento recaia na posição correta, de acordo com cada tempo verbal. Além disso, essas restrições asseguram que a localização do acento ocorra no contexto morfológico adequado ao tempo verbal analisado.

\section{REFERÊNCIAS}

BISOL, L. O acento e o pé métrico binário. Cadernos de Estudos Linguísticos, Campinas, n. 22, p. 69-80, jan./jun. 1992.

BISOL, L. O acento e o pé métrico binário. Letras de Hoje, v. 29, n. 4, p. 25-36, dez. 1994.

HAYES, B. Metrical Stress Theory: Principles and Case Studies. Chicago: University of Chicago Press, 1995.

HYDE, B. Metrical and Prosodic Structure in Optimality Theory. 2001. PhD dissertation (Doctor of Philosophy Graduate Program in Linguistics) - Rutgers University, New Brunswick, New Jersey. Disponível em: http://roa.rutgers.edu/,ROA-476, Acesso em: 12 mai. 2020.

KAGER, R. Optimality Theory. Cambridge: Cambridge University Press, 1999.

LEE, S. H. A regra do acento do português: outra alternativa. Letras de Hoje, Porto Alegre, v. 29, n. 4 , p. 37-42, 1994.

LEE, S. H. O acento primário no português: uma análise unificada na teoria da otimalidade. In: ARAÚJO, G. A. de. (org.). O acento em português: abordagens fonológicas. São Paulo: Parábola Editorial, 2007. p. 121-143.

MAGALHÃES, J. S. de. O plano multidimensional do acento na teoria da Otimidade. 2004. Tese (Doutorado em Letras) - Pontifícia Universidade Católica do Rio Grande do Sul, Porto Alegre, 2004.

MAGALHÃES, J. S. de. Acento. In: BISOL, L.; SCHWINDT, L. C. (org.). Teoria da Otimidade: Fonologia. Campinas: Pontes, 2010. p. 93-134. 
MASSINI-CAGLIARI, G. A música na fala dos trovadores: Estudos de prosódia do Português Arcaico, a partir das cantigas profanas e religiosas. 2005. Tese (LivreDocência em Fonologia) - Faculdade de Ciências e Letras, Universidade Estadual Paulista "Júlio de Mesquita Filho", Araraquara, 2005.

MASSINI-CAGLIARI, G. Do poético ao linguístico no ritmo dos trovadores: três momentos da história do acento. Araraquara: FCL, Laboratório Editorial, UNESP; São Paulo: Cultura Acadêmica, 1999.

MASSINI-CAGLIARI, G. Cantigas de amigo: do ritmo poético ao linguístico. Um estudo do percurso histórico da acentuação em português. 1995. Tese (Doutorado em Linguística) - Instituto de Estudos da Linguagem, Universidade Estadual de Campinas, Campinas, 1995.

MATEUS, M. H. M. O acento de palavra em português: uma nova proposta. Boletim de Filologia. Lisboa, Tomo XXVIII, p. 1-19, 1983.

MATEUS, M. H. M.; D'ANDRADE, E. The Phonology of Portuguese. Oxford: Oxford University Press, 2000.

McCARTHY, J.; PRINCE, A. S. Generalized Alignment. In: BOOJ, G.; VAN MARLE, J. (ed.). Yearbook of Morphology. Dordrecht: Kluwer, 1993a. p. 79-153.

McCARTHY, J.; PRINCE, A. S. Prosodic Morphology l: constraint interaction and satisfaction. Massachusetts: University of Massachusetts, Amherst and Rutgers University, 1993b.

PRINCE, A.; SMOLENSKY, P. Optimality Theory: constraint interaction in generative grammar. Rutgers University and University of Colorado-Boulder, 1993.

RUSSELL, K. Optimality Theory and Morphology. In: ARCHANGELI, D.; LANGENDOEN, D. T. (ed.). Optimality Theory: An Overview. Oxford: Blackwell, 1997. p. 102-133.

WETZELS, L. Primary Word Stress in Brazilian Portuguese and the Weight Parameter. Journal of Portuguese Linguistics, p. 9-58, 2007. 